\title{
Population Development and Demography in Finland
}

\author{
By JARL LINDGREN
}

The Population Research Institute

\section{Population Development}

The features characterizing the transition of an old agrarian society into a society dominated by industrial and service occupations have been rather late in making their appearance in the population development of Finland. The breakthrough of industrialism began in the 1870s. Population growth slowed down towards the end of the preindustrial period and strong variations in the mortality rate left their mark on population development. The industrial breakthrough and urbanization led to a demographic transition: a drop in the mortality rate and the birthrate. The mortality rate began to decline slightly before the 1870 s but the birthrate did not begin its decline until the early 20 th century: the birthrate dropped from 30 per thousand in 1910 to 19 per thousand in the thirties.

World War II turned population development in an entirely new direction. Immediately after the war the birthrate began to climb and in 1947 it was as high as in the beginning of the century. The large age groups, whose incorporation in society has been so problematic, were born. The birthrate then declined slowly but steadily and in the early seventies the crude birthrate was one of the lowest in the world - if not the lowest. At the end of the 1950's the natality ceased to decline. At the same time the crude death rate, which had been close to 20 per thousand in the early 20 th century, dropped below 10 per thousand. The drop in the fertility and the stabilization of the mortality rate caused an increase in the proportion of the elderly in the population and slowed down natural growth. Even if the reproduction rate is low the age structure is still very favorable; the 15-64-year-old age group is 66 percent. According to population forecasts this favorable situation will continue for several decades. However, fertility must increase in the beginning of the following century at the latest in order to prevent the activity rate of the population from diminishing in the long run.

When examining population development in Finland during the decades after World War II we must remember that social development has been characterized by a strong structural change which has probably been faster than in any other European country. In twenty years Finland went through a transition which took about one century in many industrialized western countries. The proportion of the economically active population employed in agriculture 
declined from 46 percent in 1950 to about 15 percent in 1975. In 195038 percent of the population lived in urban centers, in 1970 the figure was over 50 percent. For urban municipalities, 90 percent of the increase in population has actually been caused by migration. Another characteristic feature is the increasing participation of women in the labor force. The participation rate is remarkably high internationally: in 1974 the proportion of women in the economically active population was 44 percent.

In spite of declining fertility there has been an excess of births over deaths which has dropped since the end of 1950 s from 10 per thousand to 34 per thousand in the 1970 s. During the 1950 s and especially the 1960 s population growth was smaller than the excess of births over deaths because of emigration to Sweden. In 1969 and 1970 emigration rose to such heights that the natural increase was not enough to compensate for population loss. In the early 1970 s population growth was again somewhat higher than the excess of births over deaths because of return migration from Sweden.

Since the mid-20th century population growth has been almost solely a result of the declining death rate. Nevertheless, fertility has had a part in population growth despite its continuous decline up to the 1960s.

Although fertility diminishes, it is possible for the population to grow temporarily, if the changes in age structure lead to the growth of fertile age groups. A small increase has appeared in the age structure of women of childbearing age. Primarily the reasons for the influence of fertility on population growth are found in the fertility pattern which has been characterized by the shift of fertility to the younger age groups. As a result the average age of women giving birth has declined and the distance between generations has also shortened. New generations are born at a faster pace. This explains why the population keeps growing even though fertility is decreasing and mortality remains practically unchanged.

In the 1960 s the marriage rate of both sexes continued to increase in the younger age groups. As the increase in the proportion of married people appears to cease at about the age of 35, the marriage rate of people born in 1930-1940 reached its peak in the $1960 \mathrm{~s}$, this amounts to about $83 \%$ for women and $80 \%$ for men.

Like the marriage rate of the earlier cohorts, the marriage rate of the large cohorts born at the end of the 1940s grew until the end of the 1960 s, but a great decline has subsequently taken place, causing a distinct decrease in the marriage rate of persons born at the end of the forties and in the early fifties. The decline in the marriage rate of cohorts born after the large cohorts may have been brought on by factors such as a lengthening of the period of education, an increase in migration and emigration, the change in the industrial structure and the great lack of housing in the areas of in-migration, but also to some degree by the phenomenon among young people of forming a family but not getting legally married. 


\section{Fertility}

A rather constantly and quickly declining fertility has been typical of Finland since the end of the 1940s. In 1949 somewhat more than 26 children per 1000 inhabitants were born. In 1965 the corresponding figure was 17.1, and in 1973 the low point was reached with only 12.2 children per 1000 inhabitants. After that, however, a weak augmentation has been noted; in 1974 the crude birth rate was 13.3 and in 1976 it reached 14.4 and is about the same in 1977 .

The fertility rates of the oldest age groups began to decline as early as the $1950 \mathrm{~s}$, but the decline within the most important groups from the point of view of fertility did not set in until the beginning of the 1960 s, i.e. for women aged $20-29$ years. At the same time fertility began to concentrate in the younger age groups. In 1950 women before the age of 30 had given birth to $58 \%$ of their children and in $197374 \%$. The fertility rates declined most towards the end of the $1960 \mathrm{~s}$, when the total fertility rate dropped by one-fourth. At the same time the net reproduction rate dropped below the reproduction line and in 1973 the daughter generation was only $71 \%$ of the mother generation. This low figure has since risen to about $80 \%$.

The number of illegitimate births has risen steadily especially during the last few years: illegitimate live births formed 5.8 percent of all live births in 1970 and 10.1 percent in 1975 . Most or about 90 percent of all illegitimate births are the women's first-born.

Several factors caused the significant decline of fertility in the early 70 s. The main explanation, however, is the rapid development of society and the aftereffects of this transition. One reason is the loss of 200000 persons through emigration. Finnish women emigrants to Sweden currently give birth to some $5000-6000$ children a year, i.e. nearly $10 \%$ of the number of children born in Finland. If the great wave of emigration in the 1960 s had not occurred, the number of births in Finland would quite probably be some $10 \%$ higher.

In 1970, the abortion law was reformed in Finland. Prior the the reform, $5000-6000$ abortions a year were made. After the enforcement of the new law, the number of abortions rapidly rose to $22000-23000$ a year. The new law balanced out the opportunities of having abortions in various parts of the country, thus raising the number of abortions in Northern and Eastern Finland nearly tenfold, whereas the increase was only threefold in the province of Uusimaa in Southern Finland. However, several researchers maintain that the rapid increase in abortions has not had a decreasing effect on fertility, only that formerly illegally made abortions are now made legally.

Due to the lengthened period of education and the great difficulties in finding housing, it was difficult for the large cohorts to have children in their best period of fertility. As women became increasingly economically active, the lack of daycare created another obstacle. At the same time birth control methods developed rapidly, and the number of unwanted children diminished. The large cohorts were compelled to postpone having children to an exceptionally late 
age. The difficulties were further accentuated by a slump during the second half of the 1960 s when the labor demand decreased strongly with wide-spread unemployment as an unavoidable result. In the beginning of 1970 there were signs of a retardation of the structural change taking place in society. Internal migration decreased and began to stabilize. In 1972 an economic upswing was visible, which continued during 1973 and 1974. The GNP increased, unemployment diminished and housing production was intensified. In addition to the retardation of the structural change the attitudes toward family policy measures became more positive. There was much public discussion and planning of economical and social support for the family. Some of them have been accomplished step by step as has children's day care, for example. The real value of the child allowance has also been raised slightly several times. In 1974 maternity leave was increased from 72 to 174 days, etc. As a whole, however, these measures have not been particularly significant economically.

\section{Mortality}

The continued decline in mortality which had been in progress for a long period came to an end in the 1950 s when deaths dropped to 9 per 1000 of the average population. The mortality figures have then fluctuated between 9 and 10 per 1000 . The mean expectation of life at birth has risen continuously to 75.4 for females and 66.9 for men. This progress in longevity, which has been quite rapid up to the $1959 \mathrm{~s}$, seems to have stagnated now.

Mortality trends in Finland have some distinctive and even unique features. Hence, infant mortality, now 11.7 per 1000 , is one of the lowest in the whole world.

In contrast to its low infant mortality Finland has a very high adult mortality, especially among men. This unique pattern of Finnish mortality seems to be increasing rather than levelling out. In 1974 the expectation of life for Finnish males at 40 was 30.1 . This is the lowest figure of all European countries available in the 1974 Demographic Yearbook. Male excess mortality - which means the mortality of men is higher than that of women - is more or less apparent at all ages between 25 and 60 .

Consequently the difference between the mean life expectancies of men and women of the same age has continuously increased. As late as in the early 20th century, the difference between the mean life expectancies at the age of 0 years was three years in favor of women but in 1974 the difference had grown to seven years.

The real reasons that lie behind the unusually high male death rates are still greatly a matter for conjecture. Male deaths do not concentrate in any single category of disease, although cardiovascular diseases are responsible for a major proportion of deaths. This over-mortality probably has a multifactorial etiology. 
The fact that child and maternal mortality figures are quite favorable and that children and mothers are the only groups offered effective preventive medical care suggests that one of the reasons for high adult male mortality could be deficiencies in the organization of health sevices for adults and for males in particular as well as the negative attitude towards medical care adopted by Finnish men.

Regional differences in mortality are probably due largely to general socioeconomic differences, including variations in the occupational structure, dietary habits and selective migration from under-developed regions to developed regions. Low winter temperatures, soil characteristics such as a shortage of trace elements may also have some negative influence. Moreover, genetic factors can not be excluded as a partial explanation. For centuries, the Finnish population has formed a genetic isolate; although we know very little about the inheritance of the diseases that cause most morbity and mortality, it is possible that genetic isolation could be one reason for the sexcess prevalence» and death rates attributable to these diseases.

\section{Migration}

Apart from the natural increase in population, the development of the number of inhabitants is also dependent upon the frequency of migration. For a lengthy period, migration and emigration have not exerted any significant effect upon the development of the population.

As a result of industrialization the population began to move to the southwestern and southern parts of the country where harbors and the old urban centers constituted the framework for urbanization. Internal migration was fairly constant from the end of the 19th century to the beginning of the 1930 s when it began to increase: at the end of this decade internal migration consisted of about 3 percent of the population. After the war internal migration continued to rise steadily and in 1960 it was more than twice as large as before the war. In the 1970 s, the growing trend continued and reached its peak in 1974 when 276000 Finns or nearly 6 percent of the population moved to another municipality. Even though internal migration has been very intensive and has actually increased recently, it has nevertheless been more regionally balanced. Hence, in 1970 the total net out-migration from municipalities characterized by net out-migration amounted to 50000 persons. In 1974 it was 34000 and in 1975 even lower or 29000 persons.

A major reason for this development is the fact that the regional imbalance in the demand and supply of labor has been diminishing as a consequence of a more active regional policy. The conditions under which enterprises operate and the training of the labor force has both improved in northern and eastern 
Finland, etc. Moreover the age cohorts entering the labor market are smaller each year, which also eases pressure to out-migrate.

Emigration again has been a significant social phenomenon in Finland on two occasions during the last hundred years: before the First World War and after the Second World War. Between 1880 and 1914 about 300000 Finns settled in countries overseas, mainly in the United States. In the inter-war period, emigration from Finland was low because of the various obstacles (visas, work permits etc.) to international labor mobility in most countries. Since the Second World War nearly 500000 Finns have emigrated, most of them to Sweden within the framework of the common Nordic Labor Market. Allowing for return migration, net emigration has been about 270000 persons, equalling 5,5 percent of Finland's population.

In the post-war history of Finnish emigration, the years 1969 and 1970 were notable. During these two years net emigration was about 30000 persons a year, equal to 0.6 percent of Finland's population. Since then the migratory flow was nearly balanced for several years. In 1975 it totalled $5000-6000$ persons and in 1976 it was slightly higher.

The causes of emigration and return migration have not yet been exhaustively explored, although various studies made in recent years have shed light on the migrants' personal motives and on certain institutional and structural factors. In Finland's case the rapid structural change of the society during the post-war decades may be taken as the major cause of emigration pressure, while persistent labor shortages and higher wages in Sweden have acted as the main attractions. Since there were no legal barriers to mobility because of the Common Nordic Labor Market, considerable migration flows ensued especially as the geographic, social and cultural and hindrances are relatively minor.

Particularly in the northern and eastern provinces of Finland persistent structural unemployment has been an important repellent force. Accordingly, the bulk of emigration has been from areas of underemployment, low wages, high local taxes, etc. These persistent repellents have taken their effect when the Swedish reception capacity has been high — during booms. According to several studies only a minority (10 to 25 percent) of the emigrants has actually been unemployed at the time of departure. Hence it is the threat of unemployment that has caused many people to move to Sweden in search of secure employment. In turn, one of the factors maintaining the threat of unemployment is out-migration, which weakens the foundation of economic and social development in the areas of departure.

Factors hampering internal migration have also contributed to emigration. Housing shortages have prevented many from moving to the south and southwest of Finland, leaving Sweden as the only alternative. Another reason is that the demand for unskilled labor has been higher in Sweden than in Finland. 


\section{Population Research in Finland}

Demographic research can be considered a rather new phenomenon in Finland, if demographic research is understood merely as theoretical demography or as population analysis. However, if one sees demographic research as including reports on the size of the population, its geographical distribution and its general characteristics, demographic research has been a very long-established tradition in Finland. In 1749 population data collection was made compulsory by law in Sweden, of which Finland was then a part. However, as early as in 1667 the Church Law authorized parishes to register the population and population changes such as births, marriages and deaths. Hence, official population tables give rather reliable and detailed information of many population subjects from the middle of the 18th century. The local population tables, which also include other data on the population, seem to form a nearly bottomless source for historical studies, but until now rather little scientific use has been made expect for a number of meritorius studies. Interest in using this material for demographic studies is clearly increasing, however.

After the Second World War the interest in and also the need for population analysis has been more accentuated. It was not until the 1950 s, however, when a growing output of demographic studies reflecting current problems in Finnish society could be noted.

If one wants to name the fields of main interest in different periods mention could be made of internal migration sthe flight from the countryside" as the most important subject of the 1950s.

This is a topic which has maintained its position as one of the most popular during the following decades also. In the 1960 s futurology swept over Finland resulting in a great interest in population forecasts. Several population projections were drawn up on the national level by different institutes and authorities. On the local level numerous population projections were produced for the planning of regions and municipalities. One factor affecting the increase of population projections was the intensification of the activity of the regional physical planning associations which gradually began to employ persons exclusively to care for the demographic aspects of regional planning. Demographic research has gradually been extended to cover almost all demographic characteristics of the regional or the municipal population.

At the end of the 1960 s emigration began to take alarming proportions. In 1970 a state committee was established to study emigration problems and to present proposals to the authorities. Since then a great deal of funds dedicated to research work have been directed to migration research resulting in manifold studies. The mechanism of emigration and its consequences on the national level as well as for the municipality of departure have been examined fram numerous points of views. 
Decreasing fertility which reached a very law level in the beginning of the 1970 s gave impetus to several studies which shed light on the Finnish fertility pattern but also on what the implications the low birthrate are for the present and the future. The World Fertility Survey is being carried out in Finland with the main aim to examining the causes for variations in the birthrate, which can be considered a manifestation of this interest in fertility questions. Besides the important demographic phenomena such as migration and fertility attention has increasingly been focused on mortality and morbidity. Mortality, which is rather high from a European point of view, has been approached not only from a medical but also from a sociological-demographical standpoint. Another typical feature in recent demographic research seems to be a growing tendency to approach demographic problems from an interdisciplinary angle especially in relation to economical and social aspects or vice versa to take demographic viewpoints into consideration when studying societal problems. Hence the last decades have signified an accumulation of knowledge on current and future population characteristics of the whole nation, its regions and municipalities.

The contribution of Finnish demographic research to the evolution of theoretical demography has been very meagre. This could probably be explained by the fact that the motives for developing and using sophisticated mathematical methods have not been very strong as sufficiently useful and detailed data on population has been readily obtainable from official statistics. Very few studies have concerned problems of theoretical interest at least in the field of demometry. The very few doctoral theses treating demographic topics have been dissertations in statistics, social policy, geography, and history. Until now only two or three of these theses could be considered purely demographic. Until the mid-1970s demographic teaching at the academic level was more or less sporadic and dependent on the interest in population affairs shown by the professor and the institute. However, many university institutes of social sciences and statistics have given lectures and seminars in demography and population problems. In 1975, however, Finland received its first professionship in demography which was connected to sociology. Even if demography now has its own professors chair, in many respects it has not yet laid aside its swaddling clothes as is indicated by the fact that we still lack a Finnish textbook in formal demography. However, at least one is underway.

Demography in Finland can mainly be considered a field whose foremost task has been to supply administrators, planners and politicians with information they need in their planning work. The need for demographers has been small and demography has mostly been considered an auxiliary subject mainly implying an appropriate knowledge of demography and population problems. The interest in as well as the need for demography seems, however, to be increasing in many disciplines which demand more extensive training in demography, at least at a elementary level. The demand for real demographers will, however, remain rather moderate in a small country such as Finland. 